\title{
Diálogos entre o Brasil e a Convenção Americana Sobre Direitos Humanos: análise jurisprudencial no Supremo Tribunal Federal (de 1992 a 2007)
}

\author{
Dialogues between Brazil and the American Convention on Human Rights: the \\ legal survey in the Supreme Federal Court (since 1992 to 2007)
}

\section{Flavia Piovesan \\ Nathercia Cristina Manzano Magnani*}

\section{Resumo}

Trata-se de artigo que expõe os resultados parciais de pesquisa em curso sobre o diálogo travado pelo Supremo Tribunal Federal com a Convenção Americana sobre Direitos Humanos, documento central do Sistema Interamericano de Direitos Humanos (por sua vez, o nosso sistema regional de proteção). A pesquisa de análise jurisprudencial foi feita diretamente no site do STF, mediante a utilização de metodologia devidamente esmiuçada. Os resultados gerados até o momento estampam a maneira como o diálogo entre os dois (STF e CADH) se deu nos quinze primeiros anos de vigência do documento no Brasil (1992-2007) nos seguintes pontos: incidência por ano, temas enfrentados, tipos de demanda, os artigos citados, as maneiras de nomear a Convenção Americana sobre Direitos Humanos; e, finalmente, o colegiado responsável pelo julgamento.

Palavras-chave: Convenção Americana sobre Direitos Humanos. Supremo Tribunal Federal. Análise jurisprudencial. Pesquisa empírica.

\section{Abstract}

This article presents the partial results of ongoing research on the dialogue between the Federal Supreme Court and the American Convention on Human Rights, the central document of the Inter-American Human Rights System (our regional system of protection). The jurisprudential survey was conducted directly on the STF's website, using a thoroughly scrutinized methodology. The results generated so far show how the dialogue between the Supreme Court and the ACHR took place in the first fifteen years of the document's validity in Brazil (1992-2007) in the following points: incidence per year; issues faced; types of demand; the cited articles; ways of naming the American Convention on Human Rights; and, finally, the collegiate body responsible for the trial.

Keywords: American Convention on Human Rights. Federal Court of Justice. Jurisprudential survey. Empirical research.

\section{Introdução}

O presente artigo apresenta os resultados obtidos, até o presente momento, por uma pesquisa em curso sobre a aplicação da Convenção Americana sobre Direitos Humanos (doravante, simplesmente, CADH) pelo Supremo Tribunal Federal (doravante, simplesmente, STF).

O STF dialoga com a CADH? Se sim, em que quantidade e de que maneira? Eis o problema de pesquisa que está orientando a feitura da investigação a ser aqui, parcialmente, exposta.

É disseminada a ideia de que, a despeito de sua enorme importância prática, a Convenção Americana sobre Direitos Humanos é ainda pouco aplicada no Brasil (PIOVESAN; FACHIN; MAZZUOLI, 2019, p. 10). Mas quão pouco? Os gargalos são iguais em todas as matérias/áreas do Direito? Há indícios, presentes nos textos legais,

(9) Doutora e mestra em Direito pela Pontifícia Universidade Católica de São Paulo. Professora da Pontifícia Universidade Católica de São Paulo nos programas de Graduação e Pós-Graduação em Direito. Eleita para a Comissão Interamericana de Direitos Humanos da OEA (2018-2021). São Paulo - SP - Brasil. E-mail: fpiovesan@hotmail.com.

(9) Doutoranda e mestra em Direito pela Pontifícia Universidade Católica de São Paulo (PUC-SP). Ex-bolsista CNPQ, atual bolsista CAPES. Advogada, pesquisadora e professora da Fundação Escola de Sociologia e Política de São Paulo. São Paulo - SP - Brasil. E-mail: nacrimagnani@gmail. com 
que nos permitem afirmar um distanciamento ou pouco conhecimento em relação à Convenção Americana sobre Direitos Humanos? Essas foram respostas buscadas.

O levantamento de dados em processos judiciais é uma vertente da técnica "pesquisa documental", que admite ser trabalhada em investigações de perfil quantitativo e qualitativo Neste trabalho, foi o caminho metodológico escolhido por julgar-se que seria uma fonte pertinente à pergunta de pesquisa, ou seja, com capacidade de oferecer informações úteis para o esclarecimento do problema posto (SILVA, 2017, p. 277 e 282). Mais detalhes sobre o percurso metodológico se encontra em tópico apartado desta introdução.

Entende-se que o momento da realização desta investigação não poderia ser mais propício: a Comissão Interamericana de Direitos Humanos (ou, simplesmente, $\mathrm{CIDH}$ ) acaba de completar sessenta anos, ${ }^{1}$ a Convenção Americana sobre Direitos Humanos acaba de completar cinquenta $a_{n o s}{ }^{2}$ e a Corte Interamericana de Direitos Humanos (ou, simplesmente, Corte IDH) acaba de completar quarenta anos ${ }^{3}$ - e tempos de celebrações certamente são momentos férteis para balanços sobre o passado, bem como para o desenho de perspectivas e arranjos desejáveis para o futuro.

Em apertada síntese, é possível dizer que a Convenção Americana sobre Direitos Humanos, popularmente conhecida por Pacto de São José da Costa Rica, é o tratado regente do Sistema Interamericano de Direitos Humanos, ou seja, o documento central para a proteção de direitos no continente americano, especialmente na América Latina (PIOVESAN; FACHIN; MAZZUOLI, 2019, p. 9). Com texto estruturado em onze capítulos e oitenta e dois artigos, a CADH protege uma série de direitos civis e políticos, bem como os direitos econômicos, sociais, culturais e ambientais.

O Brasil depositou sua carta de adesão à CADH em 25 de setembro de 1992, a qual foi na sequência incorporada ao ordenamento jurídico brasileiro por meio do Decreto n. ${ }^{\circ} 678$, de 06 de novembro do mesmo ano. Assim sendo, há vinte e sete anos a população brasileira teve seus direitos ampliados, uma vez que a CADH se somou à Constituição Federal de 1988 e a todas as outras normas internas na fixação de standards mínimos de direitos humanos que devem ser, aqui, respeitados (não violados) e garantidos (efetivados) - sob pena de poderem ser reclamados por controle interno ou externo de convencionalidade.

Para além do fato de que a CADH possui normatividade e, portanto, exigibilidade interna consagrada, existem outras razões pelas quais é essencial que o Judiciário brasileiro dialogue, aplique, maneje, cite e incorpore em suas decisões (sentenças ou acórdãos) o texto da Convenção Americana sobre Direitos Humanos. Aqui, receberão destaque três porquês, elencados a seguir.

Em primeiro lugar, o Brasil enfrenta um padrão sistemático, histórico e estrutural de violações de direitos humanos, especialmente em relação à parcela da população composta por afrodescendentes, indígenas, mulheres, crianças e pessoas integrantes do grupo LGBTQI+. São desafios estruturais do país o combate à desigualdade social profunda e étnico-racialmente orientada (IBGE, 2019, p. 55), ${ }^{4}$ à violência epidêmica (ONU, 2019, p. 26 e seguintes $)^{5}$ e à instabilidade da democracia e do Estado de direito (WIKE; SILVER; CASTILLO, 2019). ${ }^{6}$ Somam-se a esses outros desafios contemporâneos, como o aumento da militarização, do autoritarismo, do nacionalismo, do populismo e do protagonismo de grupos religiosos conservadores.

Diante do quadro acima, a perspectiva de atuação das instituições jurídicas para o enfrentamento e a superação dessas graves violações de direitos humanos deve ser orientada no plano multinível: sistemas domésticos, regional (interamericano) e global de proteção dos direitos humanos, trabalhando de forma holística, permeável e dialógica. Disso resulta que todo juiz nacional deve, também, ser um juiz interamericano. ${ }^{7}$

A Comissão Interamericana de Direitos Humanos foi criada por resolução da Quinta Reunião de Consulta dos Ministros das Relações Exteriores em Santiago, Chile, em 1959.

2 A Convenção Americana sobre Direitos Humanos foi assinada na Conferência Especializada Interamericana sobre Direitos Humanos, realizada em São José, Costa Rica, na data de 22 de novembro de 1969.

A Corte Interamericana de Direitos Humanos foi instalada por cerimônia ocorrida em São José, Costa Rica, em 03 de setembro de 1979.

4 Segundo o relatório "Síntese de Indicadores Sociais: uma análise das condições de vida" do Instituto Brasileiro de Geografia e Estatística (IBGE): "As desigualdades de rendimento são marcantes quando a análise da distribuição do rendimento domiciliar per capita é feita para grupos de cor ou raça da população. Enquanto $16,4 \%$ da população branca estava entre os $10 \%$ com maiores rendimentos, apenas $5,0 \%$ da população preta ou parda encontrava-se nessa mesma classe de rendimentos em 2018 . O inverso acontece entre os $10 \%$ com menores rendimentos, que abarcavam $13,5 \%$ da população preta ou parda diante de $5,5 \%$ da população branca. Em um cenário de perfeita igualdade racial haveria $10 \%$ das pessoas de cada grupo de cor ou raça distribuídas uniformemente pelas dez classes de rendimento".

5 Segundo o relatório "Global Study on Homicide" da Organização das Nações Unidas (ONU), o Brasil é o segundo país mais violento da América do Sul, com índices de mortes por homicídios mais altos do que a média regional (30,5 mortes por cada cem mil habitantes).

No Brasil, o descontentamento com a democracia foi a resposta de $83 \%$ dos entrevistados, com apenas $16 \%$ dizendo se sentir satisfeito.

Importante ressaltar, inclusive, que o controle de convencionalidade deve ocorrer não apenas para afastar normas não convencionais, mas também como parâmetro para decidir da melhor maneira por força do princípio interpretativo pro homine. 
Em segundo lugar, embora seja irrefutável que cada país da América Latina guarde peculiaridades sociais, culturais, políticas e jurídicas, entende-se que os desafios estruturalmente e contemporaneamente enfrentados pelo Brasil também atravessam os outros Estados que integram a região (PIOVESAN, 2017. p. 49), igualmente marcados pelos traços do colonialismo e pelas tensões herdadas da não superação de regimes ditatoriais recentes. ${ }^{8}$ Nesse cenário, um lus Constitucionale Commune na América Latina tem emergido, e o controle de convencionalidade guarda estreita ligação com a consolidação e a disseminação desse constitucionalismo regional transformador como um novo paradigma jurídico por toda a região.

Em terceiro lugar, entende-se que mudanças na cultura jurídica (inclusive no dia a dia prático dos operadores do Direito) são vitais para o fortalecimento do Sistema Interamericano de Direitos Humanos - por sua vez, vital para a mitigação da crise dos direitos humanos que está instalada no Brasil e na América Latina.

\subsection{Percurso metodológico}

A utilização das decisões emanadas pelo órgão de cúpula do Poder Judiciário como objeto de análise pode ser bastante fácil - principalmente por serem documentos escritos, públicos e arquivados (o que acaba por fazer com que se tornem verdadeiros registros de um tempo), e, também, pelo fato de serem emanadas por órgãos colegiados (o que Ihes confere a aptidão de gerar jurisprudência e, assim, influenciar massivamente diversos outros processos).

O primeiro recorte incidente para restringir o objeto de pesquisa foi o temporal: delimitou-se o período de promulgação da CADH no Brasil (06 de novembro de 1992) como marco inicial dos acórdãos a serem catalogados pela pesquisa e o ano de 2007 (mais especificamente, 31 de dezembro de 2007) como marco final dessa etapa de investigação. Disso resulta que, nesse primeiro esforço de pesquisa, foi enfocada a primeira década e meia de vigência da Convenção Americana no Brasil - período suficiente para uma primeira aferição do posicionamento do STF frente à Convenção examinada e, também, praticamente a metade do tempo de vigência do documento no país. ${ }^{9}$

Outro importante recorte diz respeito à categoria de decisões pesquisadas: a pesquisa analisou apenas os acórdãos (decisões colegiadas), não incluindo na análise possíveis decisões monocráticas, súmulas vinculantes, decisões da presidência, questões de ordem, repercussões gerais e os informativos.

Todos os dados foram obtidos a partir do site do próprio STF. ${ }^{10}$ Mais especificamente, por meio da aba "Pesquisa", derivada do tópico "Jurisprudência". Como a intenção dessa pesquisa era ter acesso ao maior número possível de acórdãos sobre a CADH, optou-se pela utilização da ferramenta "Pesquisa livre", sem restrições por período temporal (feita em momento posterior, em que se verificou, individualmente, a data de julgamento ${ }^{11}$ de cada um dos acórdãos).

Em relação ao(s) vocábulo(s) empregado(s) para a consulta, diversos parâmetros diferentes foram testados, principalmente levando-se em conta o fato de a Convenção Americana sobre Direitos Humanos ser amplamente conhecida no Brasil por Pacto de São José da Costa Rica. ${ }^{12}$ Ao final, optou-se pela utilização de um banco de dados, construído pela soma dos resultados obtidos por meio de diversos termos distintos, de maneira a promover uma "varredura" que fosse a mais ampla possível dos casos. São eles: Convenção Americana,$^{13}$ Pacto de São José, ${ }^{14}$ Pacto de San Jose ${ }^{15}$ e CADH. ${ }^{16}$

Excluído um acórdão gerado que nada tinha a ver com o tema, ${ }^{17}$ a pesquisa chegou ao universo de 102 acórdãos. Foi, portanto, a partir desse número que os aspectos quantitativos e qualitativos foram trabalhados.

8 Nesse sentido, consultar, por exemplo, o Índice de Desenvolvimento Humano da ONU, os informes da organização Latinobarómetro sobre percepção da democracia na região e os estudos do Banco Mundial sobre violência na América Latina.

Considerando-se aqui que a pesquisa está sendo feita em 2020.

Disponivel em: http://portal.stf.jus.br/. Acesso em: 09 dez. 2019.

Nem sempre coincidente com a data de publicação.

O Decreto que promulgou a Convenção no Brasil, inclusive, menciona ambas as denominações.

13358 ocorrências, sendo a primeira de 1994 e a última de 2019. Em razão do maior número de quantidade de resultados, preteriu-se a utilização do termo "Convenção Americana sobre Direitos Humanos" (327 resultados). Observação: A busca com o termo "Convencao Americana" (sem aspas e sem a utilização do cedilha e do til), gerou idêntico número de resultados ao encontrado na busca da expressão devidamente acentuada.

14373 ocorrências, sendo a primeira de 1950 e a última de 2019. Em razão do maior número de resultados, preteriu-se a utilização do termo "Pacto de São José da Costa Rica" (306 resultados). Observação: A busca com o termo "Pacto São José" (sem aspas e sem o "de") gerou idêntico número de resultados.

1537 ocorrências, sendo a primeira de 1995 e a última de 2018. Observação: A busca com o termo "Pacto San Jose" (sem aspas e sem o "de") gerou idêntico número de resultados.

1607 ocorrências, sendo a primeira de 2002 e a última de 2018.

17 RE 220120/SP (1998), em que o vocábulo "Convenção" dizia respeito à expressão "convenção coletiva", e o vocábulo "Americana" dizia respeito a uma cidade do interior de SP. 
Todos os julgados encontrados foram devidamente catalogados e organizados em uma planilha que separou suas informações em dez campos: a) ano de julgamento; b) número do acórdão; c) tipo de ação analisada; e) ministro responsável pela relatoria; f) colegiado em que ocorreu o julgamento ( $1^{\text {a }}$ Turma, $2^{\mathrm{a}}$ Turma ou Pleno); g) discussão/assunto principal; h) artigos da CADH porventura mencionados; i) maneira pela qual a Convenção Americana sobre Direitos Humanos foi nomeada no acórdão; j) outras observações importantes - como frases de destaque sobre a CADH, por exemplo.

A partir das informações colhidas, os dados foram gerados e analisados criticamente, conforme demonstrarão os pontos a seguir.

Durante a realização da pesquisa, o site do STF apresentou algumas complexidades de manejo. ${ }^{18} \mathrm{Em}$ relação aos obstáculos encontrados, merece destaque o fato de ter que se utilizar mais de um parâmetro de busca para conseguir arregimentar o maior número de decisões possível. Isso ocorreu porque o STF não padroniza a maneira de identificar a Convenção (não obstante ela possua uma nomenclatura oficial). Sobre isso, se falará mais detidamente em momento posterior neste artigo. Ainda, muitas ementas geradas sequer mencionavam a Convenção, o que também colocou óbices a uma coleta de dados mais fluida, menos pausada.

Finalmente, é importante fazer a menção de que há que se ter o constante cuidado em deixar claro que os resultados dizem respeito ao peculiar retrato que a metodologia empregada e a leitura dos acórdãos, em datas específicas, puderam alcançar. ${ }^{19}$

\section{Desencadeamento de dados e resultados}

Conforme explicado anteriormente, esse artigo foi escrito para demonstrar os resultados de uma pesquisa que, até o presente momento, ${ }^{20}$ mapeou quinze anos de jurisprudência sobre a aplicação da Convenção Americana sobre Direitos Humanos pelo STF.

Uma vez entendidos os principais contornos jurídicos da CADH e a razão da escolha de sua aplicação pelo STF como objeto de pesquisa, parte-se, agora, para a apresentação e subsequente análise dos dados e resultados, isto é, para o retrato dos casos envolvendo a aplicação (ou não) da CADH em julgados pelo STF, entre 1992-2007, e para o exame da maneira como o órgão reagiu nesses julgamentos. Durante o procedimento de coleta dos dados, como já mencionado, os casos foram organizados a partir de diversas categorias diferentes. É justamente obedecendo a essa organização que eles serão demonstrados a seguir.

\subsection{Incidência por ano}

A análise da quantidade de casos distribuídos nos quinze primeiros anos de manejo da Convenção Americana sobre Direitos Humanos pelo STF não é linear. O gráfico abaixo demonstra os resultados obtidos:

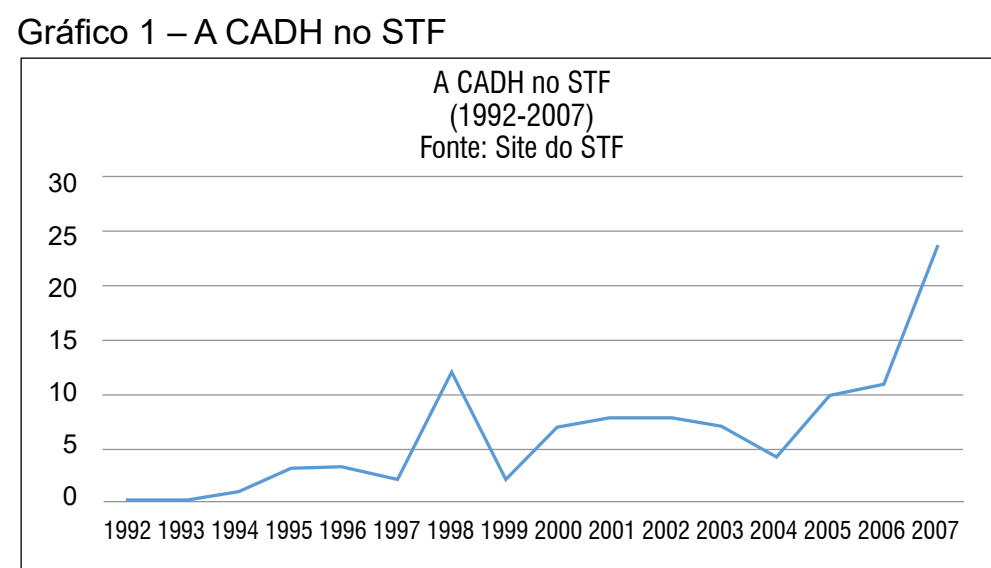

Fonte: BRASIL. STF.

18 Apesar de haver um campo com "dicas para pesquisa", o que pode tornar o trabalho de quem se aventurar pelo mundo da jurimetria utilizando essa plataforma menos dificultoso.

19 É importante lembrar que toda pesquisa estará suscetível à lógica de como o site de cada instituição é alimentado e como gera os resultados de pesquisa, o que, além de configurar mais um obstáculo de pesquisa a ser mencionado, também será outro fator influenciador no total e na qualidade das decisões amealhadas.

20 Na segunda etapa da pesquisa, aplicou-se a mesma metodologia para coletar os dados dos anos de 2008 até 2019 , fazendo-os, então, dialogar com os dados dos quinze primeiros anos de vigência da $\mathrm{CADH}$ no Brasil aqui apresentados. 
Para começar, chamou bastante atenção a pouca quantidade total de casos. Se os achados de pesquisa fossem distribuídos de maneira homogênea nos 15 anos analisados, seria como se os órgãos colegiados do STF tivessem dialogado com a CADH apenas em 6,8 casos por ano.

Durante os dois primeiros anos de vigência da CADH no Brasil, ${ }^{21}$ não foi encontrada nenhuma menção ao documento nos acórdãos do Supremo Tribunal Federal. Depois disso, temos: em 1994, 1 caso; ${ }^{22}$ em 1995, 3 casos; ${ }^{23}$ em 1996, 3 casos; $; 4$ em 1997, 2 casos; ${ }^{25}$ em 1998, 12 casos; ${ }^{26}$ em 1999, 2 casos; ; em 2000, 7 casos; ${ }^{28}$ em 2001, 8 casos; ${ }^{; 2}$ em 2002, 8 casos; ${ }^{30}$ em 2003, 7 casos; $;{ }^{31}$ em 2004, 4 casos; $; 2$ em 2005, 10 casos; $; 3$ em 2006, 11 casos; $^{34}$ em 2007, 24 casos. $^{35}$

Era uma hipótese de pesquisa que, nos últimos anos, o diálogo entre o STF e o Sistema Interamericano vinha se estreitando - e, portanto, o número de acórdãos dialogando, mencionando ou manejando diretamente com/a CADH também seria maior. Os achados de pesquisa corroboraram essa hipótese e apresentam um horizonte otimista para a pesquisa a ser realizada nos anos subsequentes a 2007.

O primeiro caso levantado em que o STF fez menção à CADH foi o HC 70398/SP, com relatoria para o acórdão do ministro Celso de Mello. Trata-se de habeas corpus relativo ao crime de tortura, com um policial militar ocupando a posição de sujeito ativo e uma pessoa menor de 18 anos a posição de sujeito passivo. $\mathrm{O}$ acórdão decidiu pela fixação da competência processual da justiça comum (em detrimento da militar), bem como pela possibilidade de punição do crime diante da existência jurídica do delito no direito penal brasileiro. Mencionou-se a CADH e outras convenções internacionais para revelar que a tipificação interna pelo Brasil foi feita para guardar fidelidade com os compromissos assumidos na esfera internacional.

Por outro lado, o último caso encontrado no período pesquisado foi o HC 92967/AC, com relatoria do ministro Celso de Mello e data de julgamento em 18 de dezembro de 2007. Nesse caso, o STF utilizou o artigo 7.2 da Convenção para possibilitar o exercício recursal em liberdade para um réu que esteve solto durante todo o processo.

\subsection{Temas}

Os acórdãos encontrados na pesquisa não registram uma grande variedade de temas. É possível dizer que a pesquisa detectou a presença da CADH no STF principalmente devido a dois assuntos, que, juntos, somam praticamente metade das ocorrências: a (i)legalidade da prisão civil do depositário infiel (31 acórdãos, o que corresponde a $30,4 \%$ do total de casos) e a possibilidade de execução provisória da pena (15 acórdãos, o que corresponde a $14,7 \%$ do total de casos).

Afora os temas supracitados, a garantia do duplo grau de jurisdição, o direito subjetivo de não ficar preso por conta do excesso de prazo na instrução processual penal e debates sobre a constitucionalidade/inconstitucionalidade do regime integral fechado na Lei de Crimes Hediondos também foram temas recorrentes, embora com menor frequência, nos achados de pesquisa.

211992 e 1993, com a ressalva de que o Decreto que a promulgou data do penúltimo mês de 1992 (portanto, era de se esperar que não fossem encontrados resultados nesse ano).

HC 7389

HC 72131/RJ, HC 72610/MG e HC 73151/RJ.

HC 73295/MG, HC 73044/SP e HC 74383/MG.

HC 74383/PR e HC 75935/MS.

HC 75687/PR, RE 205640/RS, HC 75437/RJ, HC 76698 QO/DF, HC 76346/PR, HC 76036/DF, RHC 75917/RS, HC 76561/SP, RE 206482/SP, HC 77053/SP, HC 77527/MG e HC 78344/PR.

HC 77920/SP e RE 237717/DF.

HC 79870/SP, HC 80133/PA, RHC 79785/RJ, Al 248761 AgR/RJ, RE 259506/RS, RHC 80035/SC e HC 80379/SP.

RHC 81473/SP, RE 253071/GO, RE 280398/GO, HC 80588/RJ, RE 282644/RJ, RE 285047/RJ, Al 335467 AgR/RS e Extradição 794/Paraguai.

RE 344585/RS, RE 299627/MG, RE 331159/MG, HC 81319/GO, HC 81172/RJ, HC 79376/RJ, HC 82016/PE e HC 81480 AgR.

HC 80263/SP, HC 82681/SP, RE 345345/SP, Al 403828 AgR/MS, HC 82424/RS, HC 83669/SP e HC 83416/SP.

HC 83842 / SP, HC 84716/MG, HC 84254/PI e HC 83773/SP.

33 HC 83429/RJ, Al 513044 AgR/SP, Extradição 943/Itália, HC 85237/DF, HC 85249/BA, HC 85283/ES, ADPF 54 QO/DF, HC 85298/SP, HC 85984/ SP e HC 86135/MT.

34 ADI 3741/DF, HC 87638/MT, HC 86915/SP, HC 87102/SE, HC 82959/SP, HC 86609/RJ, HC 88025/ES, HC 89429/RO, HC 89038/RS, HC 88359/ RJ e HC 86634/RJ.

35 HC 86261/RJ, HC 90074/CE, HC 89754/BA, HC 90147/SC, HC 88420/PR, RHC 90759/MG, HC 90172/SP, HC 90753/RJ, ADI 1969/DF, HC 90749/ DF, HC 88914/SP, HC 90612/SP, HC 88978/DF, HC 91657/SP, HC 91118/SP, MS 26604/DF, HC 92204/PR, MI 722 AgR/RJ, HC 90608/SP, HC 90805/GO, HC 92967/AC, MI 670/ES, MI 708/DF, MI 712/PA. 
Em relação à prisão civil do depositário infiel, como o período analisado foi anterior à mudança de entendimento pela inconstitucionalidade desse tipo de prisão, ${ }^{36}$ a CADH era mencionada basicamente para dizer que o ordenamento jurídico pátrio deveria prevalecer sobre o entendimento da Convenção. ${ }^{37}$

Já quanto ao direito de recorrer em liberdade, ou seja, da possibilidade de execução provisória/antecipada da pena, o STF flutuou de entendimento durante o período analisado. Na maior parte dos casos, a CADH foi mencionada apenas para dizer que seu texto não assegurava, de modo absoluto, a liberdade do condenado para o exercício do seu direito recursal. ${ }^{38} \mathrm{Em}$ outras ocasiões, principalmente com base no artigo 7.2 da CADH, o direito do réu de recorrer em liberdade foi assegurado. ${ }^{39}$

Por sua vez, no tocante à garantia do duplo grau de jurisdição no Brasil, o STF também se posicionou de maneira vacilante. ${ }^{40}$ Mais linearmente agiu o STF em suas decisões, em diálogo com a CADH, pelo direito de liberdade em caso de prazo não razoável de duração da instrução criminal, ${ }^{41}$ inclusive nos casos de crimes que tenham gerado clamor público. ${ }^{42}$

Afora esses assuntos, o STF também dialogou com a CADH para, entre outras pautas: sustentar a anulação de uma extradição ao Paraguai travestida de extradição política; ${ }^{43}$ deferir a presença (anteriormente negada) de acusado em audiência, como parte do exercício da autodefesa; ${ }^{44}$ impossibilitar a realização de interrogatório por videoconferência por conta da violação ao devido processo legal; ${ }^{45}$ discutir sobre o direito de petição e a necessidade de advogado para capacidade postulatória; ${ }^{46}$ discutir a tipificação do crime de tortura no Brasil|; ${ }^{47}$ repudiar a prática de crimes de racismo por antissemitismo; ${ }^{48}$ decretar ou não a inépcia de denúncias; ${ }^{49}$ julgar arbitrário o uso de algemas diante da passividade do réu. ${ }^{50}$

Um fato que chamou negativamente a atenção ao término da pesquisa foi a quase total predominância do diálogo com a CADH para julgar assuntos penais. A Convenção Americana sobre Direitos Humanos possui artigos para tratar sobre a liberdade pessoal (artigo 7) e sobre a as garantias judiciais devidas (artigo 8). Mas não só. $O$ texto também fala sobre reconhecimento à personalidade jurídica, à vida, à integridade pessoal e à honra; à liberdade de reunião, de associação, de consciência, de religião, de pensamento e de expressão; proíbe a escravidão e a servidão; assegura os direitos econômicos, sociais, culturais e ambientais; protege a família, o direito ao nome, os direitos das crianças, o direito à nacionalidade, o direito de circulação e residência, os direitos políticos, a igualdade perante a lei e o direito à propriedade privada, etc.

É reflexo direto da afirmação acima que o sistema interamericano (através de seus dois órgãos principais, ou seja, da CIDH e da Corte IDH), por meio de uma interpretação original e desafiadora, vem assegurando justiça, reparação e memória às vítimas da região em uma agenda muito mais ampla do que o espectro penal.

36 Ocorreu em 2009, por meio do julgamento dos Recursos Extraordinários 349703 e 466343 e do HC 87585.

37 Exemplo 1 (HC 73044/SP, julgado em 1995, com relatoria do ministro Celso de Mello): "Os compromissos assumidos pelo Brasil em tratado internacional de que seja parte não minimizam o conceito de soberania do Estado-povo na elaboração da sua Constituição". Exemplo 2 (RHC 80035/SC, julgado em 2000, com relatoria do ministro Celso de Mello): "A Convenção Americana sobre Direitos Humanos, além de subordinar-se, no plano hierárquico-normativo, à autoridade da Constituição da República, não podendo, por isso mesmo, contrariar o que dispõe o art. $5^{\circ}$, LXVII, da Carta Política, também não derrogou - por tratar-se de norma infraconstitucional de caráter geral (lex generalis) - a legislação doméstica de natureza especial (lex specialis), que, no plano interno, disciplina a prisão civil do depositário infiel".

38 Exemplo 1 (HC 72610/MG, julgado em 2000, com relatoria do ministro Celso de Mello): "A CADH não assegura ao condenado, de modo irrestrito, o direito de sempre recorrer em liberdade". Exemplo 2 (RHC 75917/RS, julgado em 2008, com relatoria do ministro Maurício Correa): "A ordem de prisão decorrente de decisão condenatória proferida por juiz competente não configura constrangimento ilegal ou abuso de poder. Consoante reiterado entendimento do Supremo Tribunal Federal, a determinação para expedição de mandado de prisão não conflita com o princípio constitucional da presunção de inocência (art. $5^{\circ}$, LVII) nem com a Convenção Americana sobre Direitos Humanos (Pacto de São José da Costa Rica)".

39 Por exemplo, no HC 90608/SP e no HC 92967/AC, ambos julgados em 2007, com relatoria do ministro Celso de Mello.

40 No Al 248761 AgR/RJ, de 2000, com relatoria do ministro Ilmar Galvão, disse o STF que: "Não sendo o duplo grau de jurisdição uma garantia constitucional [...]". No entanto, posteriormente, no HC 88420/PR, de 2007, com relatoria do ministro Ricardo Lewandowski, disse o STF que: "A incorporação posterior ao ordenamento brasileiro de regra prevista em tratado internacional tem o condão de modificar a legislação ordinária que Ihe é anterior".

41 Exemplo 1(HC 80379/SP, julgado em 2000, com relatoria do ministro Celso de Mello): "O excesso de prazo, quando exclusivamente imputável ao aparelho judiciário - não derivando, portanto, de qualquer fato procrastinatório causalmente atribuível ao réu - traduz situação anômala que compromete a efetividade do processo". Exemplo 2 (HC 84254/PI, julgado em 2004, com relatoria do ministro Celso de Mello): “A prisão preventiva, enquanto medida de natureza cautelar, não pode ser utilizada como instrumento de punição antecipada do indiciado ou do réu". Observação importante: Não foram todos os casos analisados em que houve pleito de soltura por excesso de prazo que terminaram com o deferimento do pedido (vide, por exemplo, o HC 83842 / SP, de 2004, com relatoria do ministro Celso de Mello).

42 Vide HC 80.379/SP anteriormente citado.

43 Extradição 794, julgada em 2000, com relatoria do ministro Mauricio Correa.

HC 86634/RJ, julgado em 2000, com relatoria do ministro Celso de Mello.

HC 88914/SP, julgado em 2007, com relatoria do ministro Cezar Peluso.

Ml 722 AgR/RJ, julgado em 2007, com relatoria do ministro Celso de Mello.

o já anteriormente mencionado HC 70389/SP (1994), com relatoria para o acórdão do ministro Celso de Mello.

HC 82424/RS, julgado em 2003, com relatoria para o acórdão do ministro Maurício Corrêa.

Por exemplo, nos HC 90749/DF e HC 88978/DF, ambos julgados em 2007, com relatoria do ministro Cezar Peluso.

HC 89429/RO, julgado em 2006, com relatoria da ministra Carmen Lúcia. 
A referida agenda envolve, entre outros temas que poderiam e podem inspirar o Judiciário brasileiro: o enfrentamento às violações dos povos indígenas; a implementação progressiva e a justiciabilidade direta dos direitos econômicos, sociais, culturais e ambientais; a leitura inconstitucional das leis de anistia; a proteção de mulheres, crianças, idosos e das diversidades sexual e étnico-racial.

\subsection{Tipo de ação analisada}

A grande maioria das ocorrências geradas pela pesquisa era de habeas corpus (71 acórdãos). Esse dado guarda bastante relação com a discussão travada no tópico anterior, isto é, com a predominância dos diálogos envolvendo demandas penais.

Gráfico 2 - Tipo de ação analisada

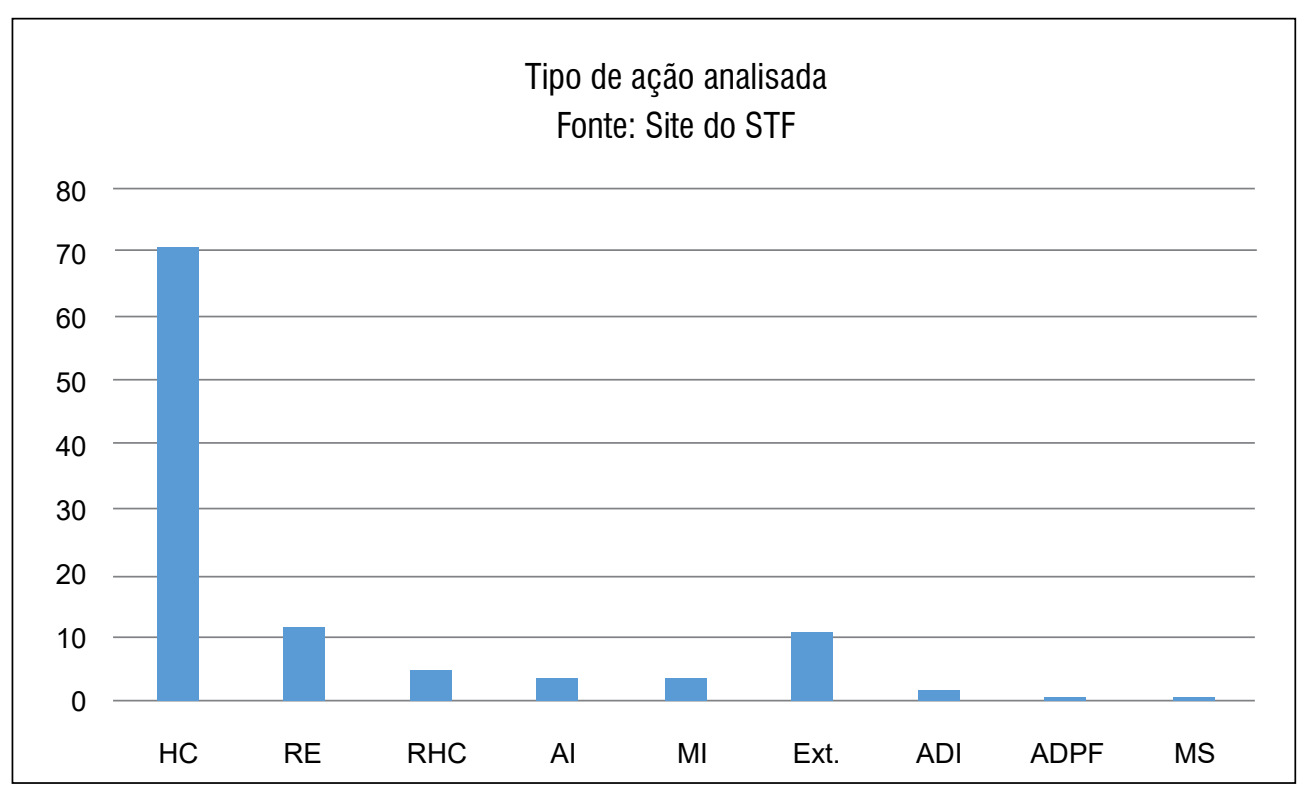

Fonte: BRASIL. STF.

Em relação aos outros tipos de ação, os achados de pesquisa foram: 12 recursos extraordinários, 5 recursos em habeas corpus, 4 agravos de instrumento, 4 mandados de injunção, 2 extradições, 2 ações diretas de inconstitucionalidade, 1 ação de descumprimento de preceito fundamental; e, finalmente, 1 mandado de segurança.

As únicas ações de controle concentrado de constitucionalidade encontradas na pesquisa foram a ADI 3741/ DF (em que foram discutidas questões eleitorais), a ADI 1969/DF (em que se determinou a inconstitucionalidade de decreto distrital que continha limitações à liberdade de reunião e de expressão) e a questão de ordem na ADPF 54/DF (em que se discutiu a possibilidade de interrupção da gravidez de fetos anencéfalos).

Em relação ao fato de que quase $70 \%$ dos acórdãos encontrados eram HCs, uma consideração crítica deve ser feita. O habeas corpus é uma ação autônoma de impugnação de natureza mandamental destinada a garantir o direito fundamental à liberdade individual (tanto em relação a ilegalidades já consumadas quanto para prevenir detenções ou constrangimentos iminentes). Não obstante seu caráter constitucional e o fato de tutelar um direito fundamental/humano de suma importância, é ação de procedimento sumário e, como tal, de cognição limitada. Em outras palavras, trata-se de writ com estreitos limites, o que, na prática, irá significar que inexiste a possibilidade de dilação probatória (LOPES JR., 2018, p. 1121).

A partir dessas informações, o evidente predomínio dos habeas corpus pode conduzir à análise de que, infelizmente, uma expressiva quantidade de casos em que o STF dialogou com a CADH não foi julgada à luz de uma cognição exauriente ou de debates mais verticalizados.

Transita-se, neste momento, ao enfoque dos artigos da CADH eventualmente citados de forma explícita pelos julgados analisados. 


\subsection{Artigos citados}

Nem todos os acórdãos citaram artigos da Convenção Americana expressamente. As citações que foram encontradas na pesquisa são: artigo $1 ; 5^{51}$ artigo $2 ; ;^{52}$ artigo $7.2 ;{ }^{53}$ artigo $7.5 ; ;^{54}$ artigo $7.6 ;{ }^{55}$ artigo $7.7 ;{ }^{56}$ artigo $8 ;{ }^{57}$ artigo 8.2, alínea "b" ; 58 artigo 8.2, alínea "d"; 59 artigo 8.2, alínea "f"; ;0 artigo 8.2, alínea "h"; ;1 artigo 17;62 artigo 22;63 artigo $22.8 ;{ }^{64}$ artigo $25 ;{ }^{65}$ e, finalmente, artigo $29 .{ }^{66}$

Analisando os artigos listados acima, é possível concluir que se destacaram os artigos ligados à obrigação estatal de respeitar os direitos humanos, bem como ao dever estatal de adotar disposições de direito interno (artigos $1^{\circ} \mathrm{e} 2^{\circ}$ ). Destacaram-se, ainda, o direito à liberdade pessoal (artigo 7), as garantias judiciais (artigo 8), a proteção da família (artigo 17), o direito de circulação e residência (artigo 22) e o direito à proteção judicial (artigo 25), com ênfase às normas de interpretação da Convenção Americana (artigo 29). Extrai-se, assim, que esse universo aponta, fundamentalmente, aos direitos civis e políticos, não havendo qualquer alusão aos direitos econômicos, sociais e culturais.

\subsection{Maneiras de nomear a Convenção Americana sobre Direitos Humanos}

Em relação à maneira como o STF se referiu à Convenção Americana sobre Direitos Humanos, os achados superaram as intuições prévias à investigação. Na maior parte dos julgados, apareceu o nome oficial e correto da Convenção Americana sobre Direitos Humanos, ${ }^{67}$ a versão em português pelo qual o documento é conhecido (Pacto de São José da Costa Rica) ou os dois termos somados.

51 Nesse caso, sem mencionar qualquer dos desdobramentos do artigo. O artigo diz respeito à obrigação de respeitar os direitos. Vide MI 722 AgR/ RJ, julgado em 2007 e com relatoria do ministro Celso de Mello.

52 "Se o exercício dos direitos e liberdades mencionados no artigo 1 ainda não estiver garantido por disposições legislativas ou de outra natureza, os Estados Partes comprometem-se a adotar, de acordo com as suas normas constitucionais e com as disposições desta Convenção, as medidas legislativas ou de outra natureza que forem necessárias para tornar efetivos tais direitos e liberdades". Vide MI 722 AgR/RJ, julgado em 2007 e com relatoria do ministro Celso de Mello.

53 "Ninguém pode ser privado de sua liberdade física, salvo pelas causas e nas condições previamente fixadas pelas constituições políticas dos Estados Partes ou pelas leis de acordo com elas promulgadas". Vide, por exemplo, HC 92967/AC, HC 90608/SP, HC 90753/RJ e HC 89754/BA todos julgados em 2007 e com relatoria do ministro Celso de Mello.

54 "Toda pessoa detida ou retida deve ser conduzida, sem demora, à presença de um juiz ou outra autoridade autorizada pela lei a exercer funções judiciais e tem direito a ser julgada dentro de um prazo razoável ou a ser posta em liberdade, sem prejuízo de que prossiga o processo. Sua liberdade pode ser condicionada a garantias que assegurem o seu comparecimento em juízo". Vide, por exemplo, HC 88914/SP (2007, ministro Cezar Peluso), HC 88025/ES (2006, ministro Celso de Mello) e HC 85237/DF (2005, ministro Celso de Mello).

55 "Toda pessoa detida ou retida deve ser conduzida, sem demora, à presença de um juiz ou outra autoridade autorizada pela lei a exercer funções judiciais e tem direito a ser julgada dentro de um prazo razoável ou a ser posta em liberdade, sem prejuízo de que prossiga o processo. Sua liberdade pode ser condicionada a garantias que assegurem o seu comparecimento em juízo". Vide, por exemplo, HC 85237/DF (2005, ministro Celso de Mello) e HC 90805/GO (2007, Celso de Mello).

56 "Ninguém deve ser detido por dívidas. Este princípio não limita os mandados de autoridade judiciária competente expedidos em virtude de inadimplemento de obrigação alimentar". Exemplos: HC 70389/SP, julgado em 1994 e com relatoria para acórdão do ministro Celso de Mello; HC 76561/SPHC, julgado em 1998 e com relatoria para acórdão do ministro Nelson Jobim; HC 91657/SP, julgado em 2007 e com relatoria do ministro Gilmar Mendes.

57 Nesse caso, sem mencionar qualquer dos desdobramentos do artigo. O artigo diz respeito às garantias judiciais. Vide MI 722 AgR/RJ, julgado em 2007 e com relatoria do ministro Celso de Mello.

58 "Toda pessoa acusada de delito tem direito a que se presuma sua inocência enquanto não se comprove legalmente sua culpa. Durante o processo, toda pessoa tem direito, em plena igualdade, às seguintes garantias mínimas: comunicação prévia e pormenorizada ao acusado da acusação formulada". Vide, por exemplo, HC 90749/DF (2007, Cezar Peluso).

59 "Toda pessoa acusada de delito tem direito a que se presuma sua inocência enquanto não se comprove legalmente sua culpa. Durante o processo, toda pessoa tem direito, em plena igualdade, às seguintes garantias mínimas: [...] direito do acusado de defender-se pessoalmente ou de ser assistido por um defensor de sua escolha e de comunicar-se, livremente e em particular, com seu defensor". Vide, por exemplo, HC 86634/RJ (2006, Celso de Mello).

60 "Toda pessoa acusada de delito tem direito a que se presuma sua inocência enquanto não se comprove legalmente sua culpa. Durante o processo toda pessoa tem direito, em plena igualdade, às seguintes garantias mínimas: [...] direito da defesa de inquirir as testemunhas presentes no tribunal e de obter o comparecimento, como testemunhas ou peritos, de outras pessoas que possam lançar luz sobre os fatos". Vide, por exemplo, HC 86634/RJ (2006, ministro Celso de Mello).

61 "Toda pessoa acusada de delito tem direito a que se presuma sua inocência enquanto não se comprove legalmente sua culpa. Durante o processo, toda pessoa tem direito, em plena igualdade, às seguintes garantias mínimas: [...] direito de recorrer da sentença para juiz ou tribunal superior". Vide, por exemplo, RHC 79785/RJ (2000, ministro Sepúlveda Pertence).

62 Nesse caso, sem mencionar qualquer dos desdobramentos do artigo. O artigo diz respeito à proteção da família. Vide, por exemplo, HC 82016/PE (2002, Ministra Ellen Gracie)

63 Nesse caso, sem mencionar qualquer dos desdobramentos do artigo. O artigo diz respeito ao direito de circulação e de residência. Vide, por exemplo, HC 82016/PE (2002, Ministra Ellen Gracie).

64 "Em nenhum caso o estrangeiro pode ser expulso ou entregue a outro país, seja ou não de origem, onde seu direito à vida ou à liberdade pessoal esteja em risco de violação por causa da sua raça, nacionalidade, religião, condição social ou de suas opiniões políticas". Vide, por exemplo, Extradição 794/Paraguai (2001, ministro Maurício Correa).

65 Nesse caso, sem mencionar qualquer dos desdobramentos do artigo. O artigo diz respeito à proteção judicial. Vide MI 722 AgR/RJ, julgado em 2007 e com relatoria do ministro Celso de Mello.

66 Nesse caso, sem mencionar qualquer dos desdobramentos do artigo. O artigo diz respeito às normas de interpretação da Convenção. Vide MI 722 AgR/RJ, julgado em 2007 e com relatoria do ministro Celso de Mello.

67 Observação: no HC 75437/RJ (1998, relatoria para o acórdão do ministro Nelson Jobim) o nome da Convenção foi grafado corretamente, mas em letras minúsculas. 
Mas, para além desses, foram encontrados mais sete outros jeitos de fazer referência ao documento, alguns, inclusive, falhos tecnicamente. São eles: Convenção Americana de Direitos Humanos; ${ }^{68}$ Convenção Americana de Direitos Humanos/OEA; ${ }^{69}$ Pacto de São José ${ }^{70}$ Pacto de San José da Costa Rica; ${ }^{71}$ Convenção de San Jose da Costa Rica ${ }^{72}$ Convenção Interamericana de Direitos Humanos; ${ }^{73}$ e, finalmente, $\mathrm{CADH} .{ }^{74}$

Como já mencionado na descrição do percurso metodológico, não haver uniformidade no que se refere à nomeação da $\mathrm{CADH}$ gerou uma dificuldade adicional na coleta dos dados, que seria mitigada se houvesse rigor técnico na adoção da nomenclatura oficial da Convenção Americana sobre Direitos Humanos.

Neste momento, passa-se ao exame do colegiado responsável pelo julgamento, se Turmas ( $1^{\mathrm{a}}$ ou $2^{\mathrm{a}}$ Turmas) ou o Pleno.

\subsection{Colegiado responsável pelo julgamento}

A pesquisa também mapeou por qual colegiado os acórdãos encontrados foram julgados - além do Pleno, o STF se divide em duas Turmas. Os resultados obtidos foram os seguintes: 34 acórdãos julgados pela $1^{\text {a }}$ Turma, 47 acórdãos julgados pela $2^{\mathrm{a}}$ Turma e 21 acórdãos julgados pelo Pleno.

Os números por si só indicam que um universo mais expressivo de casos de aplicação da Convenção Americana sobre Direitos Humanos foi localizado nos julgamentos proferidos pela $2^{\mathrm{a}}$ Turma, ao passo que o Pleno, por sua vez, apontou ao menor número de casos de aplicação da referida Convenção.

\section{Conclusão}

Para começar, a medida da aplicação da Convenção Americana sobre Direitos Humanos pelo STF que a pesquisa conseguiu retratar em quinze anos (sempre sendo necessário deixar claro que por meio das informações fornecidas pelo próprio banco de dados do órgão e mediante a escolha de uma metodologia específica) foi de, em média, 6,8 acórdãos por ano. Um olhar crítico sobre esse dado quantitativo permite, então, corroborar a difundida ideia da baixa utilização. O panorama, no entanto, parece estar, se não mudando, ao menos melhorando.

Importante pontuar, também, que não se pode dizer que essa baixa utilização ocorreu de forma igualitária entre as diversas áreas, pois foi possível verificar que houve um approach muito maior do STF com o texto da $\mathrm{CADH}$ quando os direitos a serem resguardados estavam ligados à liberdade pessoal e aos abusos cometidos pelo Estado que gravitam em torno das instituições criminais. A prevalência de habeas corpus e de menções ao artigo 7 e 8 da CADH são dados ratificadores dessa afirmação.

Em relação aos temas, certamente torna-se viável, depois da coleta de dados feita, corroborar a percepção corrente de que o debate sobre a não convencionalidade da prisão civil do depositário infiel foi assunto necessário e paradigmático na ampliação do uso da Convenção Americana sobre Direitos Humanos no Brasil (PIOVESAN; FACHIN; MAZZUOLI, 2019, p. 10). O achado de pesquisa de que 30,4\% dos casos giraram em torno dessa celeuma é bastante significativo nesse sentido.

Ao término da pesquisa, entende-se que alguns equívocos técnicos (pouco numerosos, mas existentes) na maneira de chamar a Convenção Americana sobre Direitos Humanos podem denotar baixa familiaridade ou baixa frequência de uso do documento. Ainda, que a inexpressiva quantidade de citações da CADH nas ementas (parte dos acórdãos mais disseminada) pode denotar a utilização do texto da Convenção apenas como um argumento "acessório/auxiliar", e não central, nas decisões. Mas, ambas são leituras, aqui apontadas, entre outras possíveis.

Em um caminho de textos convertidos em números e, depois, em reflexões, esse artigo espera ter contribuído para responder às perguntas colocadas e trazer novos horizontes (um pouco mais concretos) sobre as perspectivas dialógicas do Brasil com o Sistema Interamericano de Direitos Humanos.

Para as autoras, a importância da pesquisa se deve, também, ao fato de acreditarem que o Sistema Interamericano pode, além de salvar vidas (uma vez que as vítimas são a sua razão de ser), contribuir efetivamente em estabelecer standards de direitos humanos, compensar déficits nacionais e fomentar numa nova dinâmica de

68 RHC 79785/RJ (2000, relatoria do ministro Sepúlveda Pertence)

HC 86634/RJ (2006, relatoria do ministro Celso de Mello).

RHC 79785/RJ (2000, relatoria do ministro Sepúlveda Pertence)

HC 91657/SP (2007, relatoria do ministro Gilmar Mendes) ou HC 76561/SP (2002, relatoria da Ministra Ellen Gracie).

HC 72131/RJ (1995, relatoria para o acórdão do ministro Moreira Alves).

HC 88420/PR (2007, relatoria do ministro Ricardo Lewandowski), HC 88914/SP (2007, relatoria do ministro Cezar Peluso) e HC 76561/SP (1998, relatoria para o acórdão do ministro Nelson Jobim).

74 HC 81480 AgR (2002, relatoria do ministro Sydney Sanches). 
poder entre os atores sociais - tudo isso contribuindo, ao final, para a formatação de uma agenda contemporânea e transformadora no âmbito das violações aos direitos humanos.

Se for verdade que os direitos humanos constituem o principal desafio, teórico e prático, para a humanidade nos primórdios do século XXI, "a luta pela dignidade humana é a razão e a consequência da luta pela democracia e pela justiça” (FLORES, 2009, p. 20). É com as lições emprestadas de Herrera Flores que esse percurso investigatório se justifica e, por ora, se encerra.

\section{Referências}

COMISSÃO INTERAMERICANA DE DIREITOS HUMANOS. Quinta Reunião de Consulta dos Ministros das Relações Exteriores em Santiago. Chile, 1959. Disponível em: www.oas.org. Acesso em: 12 abr. 2019.

CONVENÇÃO AMERICANA SOBRE DIREITOS HUMANOS. Conferência Especializada Interamericana sobre Direitos Humanos. São José, Costa Rica, 22 nov. 1969. Disponível em: www.oas.org. Acesso em: 12 abr. 2019.

FLORES, Joaquín Herrera. A (re)invenção dos direitos humanos. Florianópolis: Fundação Boiteux, 2009. INSTITUTO BRASILEIRO DE GEOGRAFIA E ESTATÍSTICA. Coordenação de População e Indicadores Sociais. Síntese de indicadores sociais: uma análise das condições de vida da população brasileira. Rio de Janeiro: IBGE, 2019. Disponível em: https://biblioteca.ibge.gov.br/visualizacao/livros/liv101629.pdf. Acesso em: 13 dez. 2019.

LOPES JR., Aury. Direito processual penal. São Paulo: Saraiva, 2018.

MACHADO, Maira Rocha (org.). Pesquisar empiricamente o direito. São Paulo: Rede de Estudos Empíricos em Direito, 2017.

ORGANIZAÇÃO DOS ESTADOS AMERICANOS. Convenção Americana sobre Direitos Humanos. San Jose: OEA, 1969.

PIOVESAN, Flávia. lus Cconstitutionale Ccommune em América Latina: context, challenges and perspectives. In: BORGDANDY, Armin et al. (ed.). Transformative constitutionalism in Latin America: the emergence of a new lus Commune. Oxford: Oxford University Press, 2017. p. 49-65.

PIOVESAN, Flávia; FACHIN, Melina; MAZZUOLI, Valério. Comentários à Convenção Americana sobre Direitos Humanos. Rio de Janeiro: Forense, 2019.

SILVA, Paulo Eduardo Alves da. Pesquisas em processos judiciais. In: Pesquisar empiricamente o direito. São Paulo: Rede de Estudos Empíricos em Direito, 2017. p. 275-320.

UNITED NATIONS OFFICE ON DRUGS AND CRIME. Global study on homicide: extent, patterns, trends and criminal justice response. Vienna: UNODC, 2019. Disponível em: https://www.unodc.org/documents/data-andanalysis/gsh/Booklet2.pdf. Acesso em: 13 dez. 2019.

WIKE, Richard; SILVER, Laura; CASTILLO, Alexandra. Many across the globe are dissatisfied with how democracy is working. Pew Research Center, Washington D.C, 29 abr. 2019. Disponível em: https://www. pewresearch.org/global/2019/04/29/many-across-the-globe-are-dissatisfied-with-how-democracy-is-working/. Acesso em: 13 dez. 2019.

Recebido em: 13/12/2019

Aprovado em: 21/01/2020 